June 1990

\title{
Therapeutic Alliance and Involuntary Commitment of a Minor
}

\author{
Karen Dineen Wagner, M.D., Ph.D \\ University of Texas Medical Branch, Galveston Texas \\ Sharon R. Weinstein, M.D. \\ University of Texas Medical Center, Galveston Texas \\ Richard F. Wagner, Jr., M.D. \\ University of Texas Medical Center, Galveston Texas
}

\section{Follow this and additional works at: https://jdc.jefferson.edu/jeffjpsychiatry \\ Part of the Psychiatry Commons \\ Let us know how access to this document benefits you}

\section{Recommended Citation}

Wagner, M.D., Ph.D, Karen Dineen; Weinstein, M.D., Sharon R.; and Wagner, Jr., M.D., Richard F. (1990) "Therapeutic Alliance and Involuntary Commitment of a Minor," Jefferson Journal of Psychiatry. Vol. 8 : Iss. 2 , Article 4.

DOI: https://doi.org/10.29046/JJP.008.2.001

Available at: https://jdc.jefferson.edu/jeffjpsychiatry/vol8/iss2/4

This Article is brought to you for free and open access by the Jefferson Digital Commons. The Jefferson Digital Commons is a service of Thomas Jefferson University's Center for Teaching and Learning (CTL). The Commons is a showcase for Jefferson books and journals, peer-reviewed scholarly publications, unique historical collections from the University archives, and teaching tools. The Jefferson Digital Commons allows researchers and interested readers anywhere in the world to learn about and keep up to date with Jefferson scholarship. This article has been accepted for inclusion in Jefferson Journal of Psychiatry by an authorized administrator of the Jefferson Digital Commons. For more information, please contact: JeffersonDigitalCommons@jefferson.edu. 


\title{
Therapeutic Alliance and Involuntary Commitment of a Minor
}

\author{
Karen Dineen Wagner, M.D., Ph.D. \\ Sharon R. Weinstein, M.D. \\ Richard F. Wagner, Jr., M.D.
}

\begin{abstract}
Children are legally entitled to be present throughout the commitment hearing for continued hospitalization. The effect of this process on the therapeutic alliance between the child and the psychiatrist warrants examination. A case study of a 14 year-old boy who participated in the court proceedings is presented. The outcome of the hearing resulted in a disruption of the therapeutic alliance. Alternatives to current commitment procedures for minors are discussed.
\end{abstract}

\section{INTRODUCTION}

The due process clause of the Fourteenth Amendment holds that liberty may not be deprived without due process of the law. For civil commitment, due process provides the right of the patient to be present, to be heard, and to defend himself or herself with the assistance of an attorney during the court proceedings. In the majority of commitment hearings, the patient's psychiatrist and treatment team provide testimony to substantiate the need for the patient's continued hospitalization. A face-to-face adversial position is established between the patient and the treatment team both advocating antithetical outcomes. The patient wants to be discharged from the hospital, while the therapeutic team wants hospitalization to continue. Based on the evidence presented by the opposing parties, the court decides whether or not to continue hospitalization.

The effect of this adversarial proceeding on the therapeutic alliance for adult patients has been illuminated by Eisenberg, Barnes \& Gutheil (1). Negative effects ranged from an intense strain on a previously developing alliance to a complete breakdown of a preexisting alliance. Other negative effects reported of this adversarial process are a compromise of therapeutic trust and rapport (2).

Correspondence may be sent to Dr. Karen Wagner, University of Texas Medical Branch, Division of Child and Adolescent Psychiatry, Graves Building Room 1.104 D-25, Galveston, Texas 77550. Telephone 409/761-2419. 
There has been little attention to the effect of commitment on the therapeutic alliance when minors are involved. Although Eth discusses two cases of 17 year-old girls who petitioned the court for hospital release shortly after hospitalization (3), these cases do not speak directly to the issue of effect on the therapeutic alliance. At the time of the court hearings, alliance had not been established between the girls and their psychiatrists.

In this report, a case of a minor is described who participated in the commitment process for continued hospitalization. In this instance there was an established therapeutic alliance between the minor and his psychiatrist prior to the court hearing. The effect of the commitment process on the therapeutic alliance is examined.

\section{CASE REPORT}

A 14 year-old boy was admitted voluntarily by his parents to a psychiatric facility following episodes of sexual relations over a six month period with his 9 year old sister. He was found to be dysphoric, self-deprecatory, and chronically enraged and resentful. Under stress, his perceptions were distorted and his judgment was impaired. He received individual psychotherapy three times weekly. In therapy sessions, the patient's lack of appreciation of his psychological problems was striking. He was, however, developing a therapeutic alliance as evidenced by his desire to attend therapy sessions and his poignant discussions about his experience of emotional isolation from his family. On the basis of a lengthy inpatient comprehensive diagnostic evaluation, the treatment recommendation was continued hospitalization followed by residential treatment center placement. The patient's father objected to this recommendation, and he decided precipitously to remove this child from the hospital. The father's denial of the patient's illness was based largely upon the father's guilt and fear of further exacerbation of preexisting marital and family discord. The patient agreed with his father's decision to remove him from the hospital. The treatment team was convinced that the patient was an imminent risk of further harm to his sister and to himself, given his aggression, impulsivity, poor judgment, and capacity for perceptual distortions. A petition for commitment was filed in court by his psychiatrist. In the model of treatment for that unit for children and adolescents, the patient's treating psychiatrist also functioned as his administrator; there was no "therapist/administrator" split.

The patient and his parents were aware that any information from the present hospitalization would be admissible in court. At the time of a minor's admission to the child and adolescent unit, the parents sign written consent for admission and treatment on a conditional voluntary basis based on the general laws of the state. Specifically, they agree to the following: "I understand that his/her medical record and his/her communications, both oral and written, will be confidential and will be disclosed only with my permission except in the event that disclosure is necessary to a commitment and or guardianship hearing or as 
otherwise required by law." In this way, the patient and parents are informed that communications would not be priviledged in these hearings.

Prior to the hearing, the patient was fully informed by his psychiatrist about the purpose and the process of the court hearing. The commitment hearing was held over a two day period encompassing six hours. Present at the hearing were the judge, the patient, the parents, the treating psychiatrist, the supervising psychiatrist, the psychologist, the social worker, the nursing staff, the patient's attorney, and the hospital attorney. The hearing was conducted in a conference room at the hospital. The judge was robed and seated at a table with two desk top American flags. A reel-to-reel tape recorder with a microphone positioned on the desk was recording throughout the proceedings. All witnesses were formally sworn in. This is standard procedure for commitment of minors at this institution.

The supervising psychiatrist was requested by the judge to provide an overview of the patient's history and current clinical condition. The focus of the testimony was on the potential risk of harm posed by the patient to himself and to others outside of the hospital setting. It was emphasized by the psychiatrist that there was no less restrictive treatment setting that would be clinically appropriate for the patient. Lengthy cross examination was conducted by the patient's attorney, and it was necessary for the psychiatrist to supply detailed examples of the patient's past and current impulsive and dangerous behaviors that reflected his impaired judgment.

The psychologist described the psychological testing results in detail. The patient was described as an extremely guarded boy who struggled with intense feelings of aggression. In affect-laden situations, hostile and destructive feelings that contributed to disorganized thinking emerged from the patient. Overall, he was reported to be a dysphoric, seriously disturbed boy.

The psychiatrist with whom he had individual therapy three times per week during the hospitalization described, at the request of the attorney, the content of the therapy sessions, the patient's mental status, personality dynamics, diagnosis, case formulation, treatment recommendations, and prognosis. Overall, the patient was described as a dysphoric boy with marked underlying rage and poor impulse control who required continued hospitalization in order to prevent harm to himself and others.

The patient testified about his past problems and rebutted the adverse testimony provided by the treatment team. He reexplained past aggressive episodes as playing with no intent of harm. He took issue with many of the statements made by his treatment team. His comments focused on peripheral aspects of the testimony rather than on the major problem areas. For instance, he wanted it to be known that he liked to play basketball despite his treating psychiatrist's comment that he had few interests.

On the basis of the testimony presented during the hearing, the judge committed the patient to the hospital for a period of six months or until there was no longer a likelihood of serious harm by reason of mental illness.

Following the court hearing, the patient was reluctant to attend further 
therapy sessions with his treating psychiatrist. In sessions, he was either irritable and angry, or withdrawn. He stated that in the court hearing, his treating psychiatrist had "nothing good to say" about him. He believed that many of his behaviors were misrepresented by his psychiatrist. On the unit, he was angry, defiant, and often passive-aggressive. He stated to his teacher, who was not present at the hearing, "It was them against me." He showed no increased insight into his psychiatric disorder. Over the ensuing weeks, his anger toward unit staff dissipated to a mild extent. He remained mistrustful of his psychiatrist. The therapeutic alliance that was present prior to the commitment hearing deteriorated following the hearing. Despite efforts made by his psychiatrist, the therapeutic alliance was never reestablished during his continued hospitalization.

\section{DISCUSSION}

This case illustrates the potential for a negative effect on the therapeutic alliance when a minor is present during commitment hearings. During these hearings, testimony to support continued hospitalization is presented by the treatment team. For this patient, it was an issue of diametrically opposed interests, i.e. "them against me," with no one from his treatment team to provide support for his position. His statement "They had nothing good to say about me," reflected the emphasis of the adverse testimony about the patient's limitations and deficits.

One can surmise the insult to the patient's ego integrity and self-esteem as each treatment team member provided further unfavorable information about him in court. Ordinarily, problematic areas are discussed with the child by the psychiatrist and treatment team during the entire course of hospitalization. The information is presented in language that is meaningful and useful to the child. The quantity and timing of information presented is based upon the specific cognitive and developmental capacities of a given child. The therapeutic work is aligned with the child's ego and strengths with recognition of the child's particular vulnerability and anxieties. In the commitment process, information that may be damaging to the child's self-esteem and ego development is often forced by the court to be presented prematurely and with a degree of intensity that may be psychologically overwhelming to the child. In this case, for two days, the patient heard his treating psychiatrist, the supervising psychiatrist, and his psychologist discuss his past history, current problems, personality dynamics, diagnosis, and prognosis. A point not to be minimized is the child's actual sight of the psychiatrist and treatment team members presenting testimony. The process of seeing the psychiatrist present unfavorable information, and request continued hospitalization highlights the adversarial position between the child and the psychiatrist. One potential outcome, as illustrated by this case, is a disruption of the therapeutic alliance.

It is well known that therapeutic alliance is a key factor in effective psycho- 
therapy $(4,5)$. This case argues for alternatives to current court commitment proceedings for minors. The routine presence of a child throughout the commitment hearing warrants reconsideration in light of the potential for a negative effect on the therapeutic alliance.

Although due process entitles the child to be present at commitment hearings, the potential for psychological harm may far exceed the intended legal benefit. In some instances, the clinical needs of the child may be in direct opposition to the child's legal rights. Stone in a thoughtful discussion of advocacy, addresses the distinction between the two (6). Given the fragility of a child's ego, it is difficult to image a child who would be able to withstand the onslaught of damaging testimony without some negative consequences.

There are several alternatives to this dilemma. The present system might allow the child to speak directly with the judge rather than attend the entire hearing. This procedure would benefit the child by enabling the child to present his or her viewpoints. Since the child would not be present during the psychiatrist's testimony, it is less likely that the therapeutic alliance between the child and psychiatrist would be disrupted. In the child's absence, the child's attorney would represent the child's legal interest. Another alternative, informalization of the court process, is supported by Weinapple, Keefe \& Manto based on their experience of judicial review of admissions (7). In their facility, the judge is attired in street clothes, witnesses are sworn in at one time while the child is outside the room, attorneys ask sensitive questions without the child present and a discussion occurs among the judge, the patient, and the attorney. Informalization of the commitment process may promote maintenance of the therapeutic alliance between the child and the psychiatrist since it minimizes the adversarial process. Thirdly, it may be possible to maintain the therapeutic alliance if the child's psychiatrist is absent from the commitment proceedings. A mental health professional who is outside of the milieu could provide testimony at the court hearing based on a review of the record and consultation with the child's psychiatrist. A suboptimal alternative is to reassign the child to an uninvolved psychiatrist following an adversial legal proceeding. This alternative recognizes that the therapeutic alliance may have been irrevocably harmed.

The efficacy of these proposals for maintaining therapeutic alliance in children requires empirical investigation. However, the negative impact of current adversial proceedings on the therapeutic alliance demands remediation.

\section{REFERENCES}

1. Eisenberg GC, Barnes BM, Gutheil TG: Involuntary commitment and the treatment process: a clinical perspective. Bulletin of American Academy of Psychiatry and Law $8: 44-55,1980$

2. Halleck SL: The ethical dilemmas of forensic psychiatry: a utilitarian approach. Bulletin of AmericanAcademy of Psychiatry and Law 12:279-288, 1984

3. Eth S: Adolescent Separation-Individuation and the court. Bulletin of American Academy of Psychiatry and Law 11:231-238, 1983 
4. Allen JG, Tarnoff G, Coyne L: Therapeutic alliance and long-term hospital treatment outcome. Comprehensive Psychiatry 26:187-194, 1985

5. Clarkin JF, Hurt SW, Crilly JL: Therapeutic alliance and hospital treatment outcome. Hospital and Community Psychiatry 38:871-875, 1987

6. Stone AA: The myth of advocacy. Hospital and Community Psychiatry 30:819-822, 1979

7. Weinapple M, Keefe JE, Manto, PG Jr: Legal and psychiatric issues on the hospitalization of children; the New Jersey experience. Bulletin of American Academy of Psychiatry and Law 7:78-94, 1979 